\title{
Erratum to: Use of A-train satellite observations (CALIPSO- PARASOL) to evaluate tropical cloud properties in the LMDZ5 GCM
}

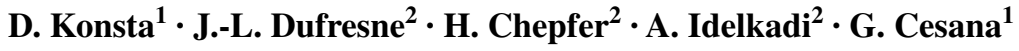

Published online: 3 March 2016

(C) Springer-Verlag Berlin Heidelberg 2016

\section{Erratum to: Clim Dyn \\ DOI 10.1007/s00382-015-2900-y}

The authors would like to correct errors in the original publication as detailed below:

In Appendix 2:

In the section "Optical properties", the citation Fig. 10a should be replaced by Fig. 9a.

In the second paragraph of the section "Radiative transfer computations", the citation Figure 10b should be replaced by Figure $9 b$.

In the section "PARASOL simulator", the citation Fig. 9 should be removed.

Figures 9-12:

Figure 9 was placed in section 4 , while it should be placed in Appendix 2.

Figures 10, 11, and 12 were placed in Appendices 1-2, while they should be placed in Appendix 3 .

The online version of the original article can be found under doi:10.1007/s00382-015-2900-y.

D. Konsta

dimitra.konsta@1md.polytechnique.fr

1 Laboratoire de Météorologie Dynamique (LMD), Ecole

Polytechnique, Palaiseau, France

2 LMD/IPSL, CNRS, Université Pierre et Marie Curie, Paris, France 